\title{
The Use of the International Classification of Functioning, Disability and Health (ICF) Framework on Educational Planning: Promoting an Environmental Approach
}

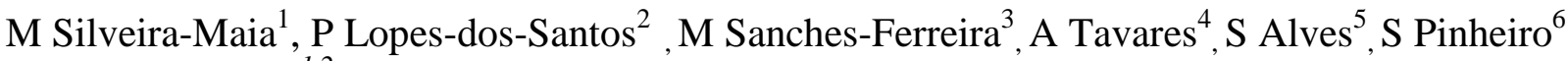 \\ ${ }^{1,2}$ School of Psychology and Education, University of Porto \\ 3, 4, 5, ${ }^{6}$ Porto Polytechnic School of Education, Polytechnic Institute of Porto
}

\begin{abstract}
Portugal was the first country decreeing the formal use of the International Classification of Functioning, Disability and Health (ICF) framework as basis for guiding assessment and planning processes within the special education field. Compared to traditional approaches, the ICF places a greater emphasis on understanding environmental contexts and their influence on human functioning. The aim of this study was to analyze the impact of its use on improving the environmental approach on assessment and intervention processes. A content and semantic analysis was carried out on 280 IEPs designed before and after the ICF use for 140 students in need of special supports. Results revealed that the assessment process of a same student included a wider spectrum of environmental factors when designed using ICF framework. This step forward on assessment processes still needs to trigger the person-environment fit perspective on intervention planning. The analysis of environmental factors' influence on students functioning (Body Functions and Activities and Participation) is seen as the guiding principle for the ICF use improvement supporting the IEPs design.
\end{abstract}

\section{Introduction}

Special education approaches have been shaped by the way limitations in students' functioning are described and conceived. The shift from deficitbased models of disability to a person-environment fit perspective calls for major changes in outlining the provision of special education services [1].

The person-environment fit framework draws on the notion that disability is not the manifestation of a defect within the individual but rather an occurrence evidenced by a poor fit between a person's capabilities and the context in which he or she has to function [2,3]. This view is consistent with current biopsychosocial paradigm, which contends that biological, personal, and environmental factors are interactively involved on human functioning and development [4-7].

A fundamental premise of the personenvironment fit model is that the environment plays a central role influencing children's learning and achievement [2, 3]. Therefore, educational plans should take into account the gaps between students' repertoire of competencies and the environment [1-3, 8]. The implication for special education teachers is to concentrate efforts on voiding the gap between capacity and environmental context so that children with additional support needs may meaningfully participate in school settings and thereby enhance their engagement in learning activities [1-3,9]. Several studies document that students' performance and abilities can be positively changed by improving environmental opportunities $[8,9]$.

Establishing the focus on promoting a better fit between student's capacities and the educational context the person-environment fit approach has the potential of increasing the quality of inclusive practices and consequently respond to the ethical demands that postulate everyone's right to be part of social valued activities and roles [10-13].

Although current educational approaches incorporate the importance of environmental factors, its recognition on daily practices has been less obvious. Documentation of environmental factors has been taking the form of recording child's surrounding environments as static variables, being uncritical to its influence on facilitating or hindering student's participation [14,15].

Researchers have been making a substantial effort to make the environmental approach workable, by listing environmental elements, which may influence the disablement process, and by characterizing its impact on functioning and disability experiences [16]. In the development of environment category schemes, different methodologies have been used, since summarizing types of modifications and adaptations to support students' inclusion (e.g., simplification of activity, special equipment) [17-19] to identifying environment dimensions that act to either impede or facilitate participation [20]. 
Based on an integrative biopsychosocial model, the ICF (World Health Organization, 2007) explicitly incorporates a comprehensive list of environmental factors, recognizing its ongoing influence on functioning [5]. The categorization of environment defined by the ICF, includes a distinction between environmental factors as either barriers or facilitators, and an exhaustive list of environmental categories - alpha-numeric codes - organized into five chapters: products and technology; natural environment and human made changes; support and relationships; attitudes; and services, systems, and policies [5].

In Portugal, the decree-law 3/2008 introduced the ICF as assessment and intervention framework in special education field [21]. State guidelines broaden the focus beyond the impairment, to undertake the description of students functioning profile and environmental factors as the basis for eligibility and intervention processes [21]. Policy makers believe that the proper use of environmental factors within the ICF will contribute to the development of more holistic and relevant educational programs [22].

The efforts undertaken by the Portuguese educational community in implementing this change impelled us to analyze how this classification system is being used in the IEPs and how its potentialities can be fully implemented on daily practices.

Comparing IEPs designed for the same students before and after the ICF use, we aim to analyze if there were changes regarding the increase of environmental references on IEPs descriptions of assessment and intervention processes.

\section{Method}

\subsection{Participants}

The sample included 280 IEPs regarding 140 students who attended special education services (two IEPs for each student). For each case, one IEP was designed before the promulgation of the Portuguese decree-law number $3 / 2008$, and the other after the promulgation of the new law. Thus, the IEPs were matched in relation to distinct views concerning individualized educational plans - i.e., prior to, and subsequent to the introduction of the ICF conceptual framework for assessment and intervention planning.

Schools from the North, Center, and South regions of Portugal provided the examined IEPs. These documents were written for students with a mean age of 10 years old, ranging from 6 to 22 years old. The sample was mainly from elementary schools.

The gender distribution was $58.6 \%$ boys and
$41.4 \%$ girls. They presented different primary health conditions such as intellectual disability (17.1\%), Down syndrome $(11.4 \%)$, cerebral palsy $(10.7 \%)$, global developmental delay $(10.7 \%)$, pervasive developmental disorders (7.9\%), and ADHD (6.4\%).

Educational responses assigned to the IEPs comprehended: (a) support provision with no changes on the regular curriculum $(8.5 \%)$, (b) accommodation of specific contents on the regular curriculum $(32.9 \%)$, and (c) modification of general curriculum goals $(58.6 \%)$. The teams responsible for the IEPs design incorporated three members in average, commonly the special education teacher, the regular teacher and the children's parents.

\subsection{Data Analysis}

IEPs were examined using content analysis. "Units of meaning" were identified and deductively categorized in reference to ICF codes, which are broadly organized into five components (Table 1).

IEPs developed after the new law endorsement were submitted to manifest content analysis - as described by Graneheim and Lundman [23] - since the use of ICF "language" was expected on them. Concerning the IEPs developed before the decreelaw 3/ 2008, the categorization process used a latent content analysis applying Cieza's linking rules [24]. This deductive analysis allowed the counting and measuring of the discourse incidence on environmental factors before and after the ICF use.

Table 1. ICF components considered on content analysis [9]

\begin{tabular}{ll}
\hline Body Functions & $\begin{array}{l}\text { "Physiological functions of body systems, } \\
\text { including psychological functions" }\end{array}$ \\
\hline Body & "Structural or anatomical parts of the body \\
Structures & $\begin{array}{l}\text { classified according to body systems" } \\
\text { clans, }\end{array}$ \\
\hline Activities and & "Execution of a task or action by an \\
Participation & $\begin{array}{l}\text { individual" and "Involvement in a life } \\
\text { situation". }\end{array}$ \\
\hline Environmental & "Aspects of the extrinsic world that form the \\
Factors & $\begin{array}{l}\text { context of an individual's life and as such, } \\
\text { have an impact on that person's functioning." }\end{array}$ \\
\hline
\end{tabular}

In order to analyze the units of meaning focused on environmental factors and their relationships with units centered on students' functioning components Body Functions and Activities and Participation -, semantic discourse analysis was carried out on IEPs texts. Relations were considered when propositions mentioning environmental factors were linked to functioning components ("He can write (d170) with peers support (e325)"). To identify these linkages we took into account the sentence order (e.g. "she has difficulties in staying concentrated and quiet. In the 
classroom, she gets worse during unstructured periods") and the use of connectives (i.e., conjunctives, adverbs, adverbial compounds) [25].

To further examine the nature of environmental references, the units of meaning were also deductively categorized into five classes defined by Whiteneck et al. [20] according to their impacts on people with disabilities (Table 2).

\begin{tabular}{|c|c|}
\hline Accessibility & $\begin{array}{l}\text { "Aspects of the environment either restrict or } \\
\text { facilitate an individual's ability to move about } \\
\text { freely in his or her community" (e.g.," } \\
\text { classroom clear from obstructions and wide } \\
\text { enough to accommodate a wheelchair") }\end{array}$ \\
\hline Accommodation & $\begin{array}{l}\text { "Aspects of the environment either restricts or } \\
\text { facilitates an individual's ability to participate } \\
\text { in an activity once he or she is at the location } \\
\text { of that activity." (e.g., "gradually increase the } \\
\text { tasks complexity"; "providing large print } \\
\text { materials") }\end{array}$ \\
\hline $\begin{array}{l}\text { Resource } \\
\text { availability }\end{array}$ & $\begin{array}{l}\text { "Availability and provision of services and } \\
\text { resources made necessary by the particular } \\
\text { disability". (e.g., "Having special education } \\
\text { responses"; "having a communication board") }\end{array}$ \\
\hline Social support & $\begin{array}{l}\text { "Attitudes and prejudices of others which } \\
\text { either discourage community integration or } \\
\text { provide a supportive environment that allows } \\
\text { community integration to flourish." (e.g., } \\
\text { "Teacher reinforce student's efforts"; "Peers } \\
\text { encourage student's participation on } \\
\text { playground games") }\end{array}$ \\
\hline Equality & $\begin{array}{l}\text { "Degree to which the policies and regulation } \\
\text { of governments and institutions insure } \\
\text { equality of opportunity for people with } \\
\text { disabilities." (e.g., "All school activities are } \\
\text { planned considering the participation of } \\
\text { student's with special needs") }\end{array}$ \\
\hline
\end{tabular}

\subsection{Reliability}

Working independently on a set of 60 IEPs a second coder categorized the units of meaning. Disagreements were resolved in debriefing sessions. Overall intercoder agreement was high:

- the average of Cohen's kappa coefficients for the ICF linked codes was of .78 and of .68 for the identified relationships between environmental factors and functioning components;

- the Pearson's correlation coefficients for environmental factors categorization into Whiteneck's dimensions ranged from .58 and .92

\section{Results}

In order to discuss whether the ICF use promotes a greater emphasis on environmental factors on IEPs' assessment - translated into students' functioning profiles - and intervention planning, qualitative analysis was performed. According to our research questions, the findings were organized into four topics: (1) extent of environmental references on assessment and intervention processes; (2) linkage of environmental references to student's functioning; (3) congruence between environmental factors used on intervention and the assessment information; (4) nature of environmental factors documented on assessment and intervention processes.

The differences between both phases - before and after ICF - and between references to ICF components and constructs were analyzed using inferential statistics:

- paired sample $t$ test. Estimated effect sizes (Cohen's d) were calculated for each reported significant outcome;

- and multivariate analysis of variance (MANOVA) for repeated measures. When rejected null hypothesis, two-sided univariate tests with a correction for multiple comparisons were done (Bonferroni test) to locate the significant differences.

\subsection{Presence of environmental references on assessment and intervention processes}

Concerning the environmental focus of IEPs, our first analysis concerns the number of environmental references on assessment and intervention processes conducted before and after the ICF use (figure 1).

Compared to the previous ones, IEPs written after the ICF use included more environmental references in the students' functioning profile, $t(139)=12.18 ; p<.001, d=.95$, and in the intervention plans, $t(139)=3.44 ; p=.001, d=.24$.

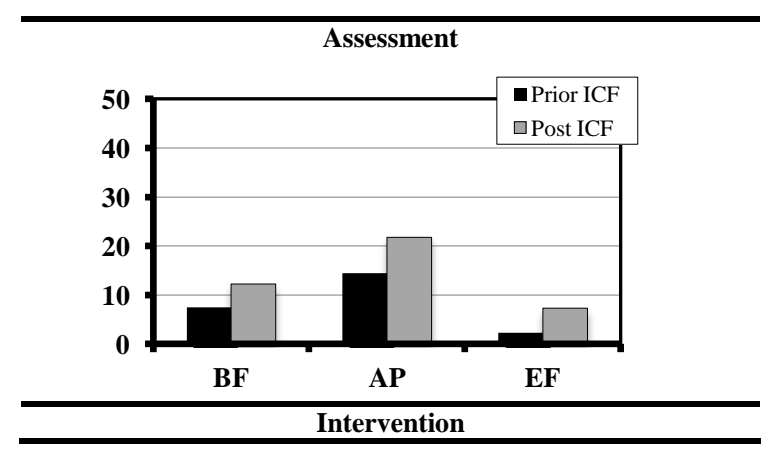




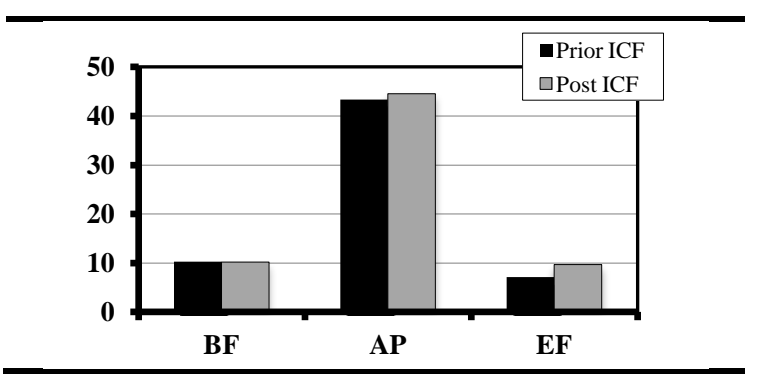

Figure 1. Mean references to each ICF component Body Functions (BF), Activities and Participation (AP) and Environmental Factors (EF) - on IEP's assessment and intervention processes

Given the post ICF significant increase of references to all components on students functioning profile, we analyzed the difference between means of environmental and the other components references. Results of the F-test in multivariate analysis of variance (MANOVA) revealed that the overall difference between the three components was significant, $F(2,138)=164.06 ; p<.001, \eta_{\mathrm{p}}{ }^{2}=.54$. Multiple range testing using Bonferroni test with $\alpha$ set at 0.05 showed that the environmental component was less mentioned than Activities and Participation $(p<.001)$ or Body Functions $(p<.001)$ components. However, there was an increase in the number of mentions to environmental elements with ICF use.

On intervention planning, equal attention was provided to Environmental Factors and to Body Functions, with no significant differences between references to these two components before and after the ICF. Activities and Participation was the most referenced component in assessment and intervention processes on both phases - prior and post ICF use.

Mention to environmental facilitators and barriers

Within assessment processes, we analyzed if the extended attention to environmental conditions included not only the description of positive and supportive factors but also the identification of barriers hindering students' participation.

As figure 2 shows, there was an increased number of references to environmental facilitators mentioning, $F(1,139)=304.04 ; p<.001, \eta_{\mathrm{p}}{ }^{2}=.69$, and barriers $F(1,139)=150.96 ; p<.001, \eta_{\mathrm{p}}{ }^{2}=.52$, between prior and post ICF moments. This increase was higher on regard to facilitators references: significant interaction effect and high magnitude of relation between the constructs and both moments was verified, $F(1,139)=79.13 ; p<.001, \eta_{\mathrm{p}}{ }^{2}=.36$.

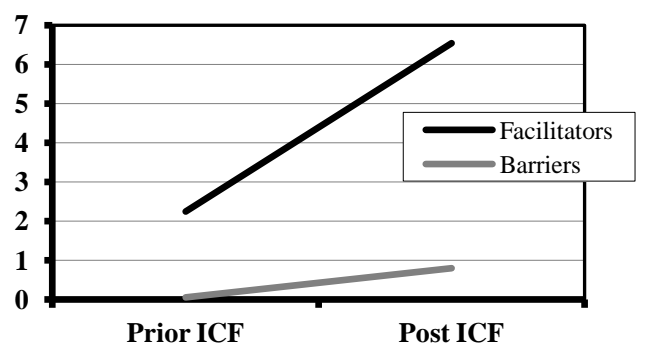

Figure 2. Mean references to each environmental constructs - facilitator and barrier - on assessment processes

Both before and after the ICF use, mentions to environmental elements were mainly to facilitator elements. There were no references to environmental barriers on assessment processes developed before the ICF. Post ICF functioning profiles still mainly focused on the description of facilitators comparing to barriers mention, $t(139)=17.44 ; p<.001, d=1.47$.

\subsection{Linkage of environmental references to student's functioning}

The units of meaning identified as reporting a relationship between environmental factors and functioning components were categorized into 4 types of relation (Table 3 ).

Table 3. Documented types of relation between environmental factors and functioning components on assessment processes (examples)

\begin{tabular}{|c|c|}
\hline Facilitators & Barriers \\
\hline $\begin{array}{l}\text { 1. Environmental factors with } \\
\text { positive effect on Activities } \\
\text { and Participation (e.g., the } \\
\text { closeness of his seat from the } \\
\text { teacher's desk }{ }^{\text {el300 improves }} \\
\text { his concentration }\end{array}$ & $\begin{array}{l}\text { 1. Environmental factors with } \\
\text { negative effect on Activities } \\
\text { and Participation (e.g., excess } \\
\text { of stimuli in the classroom }{ }^{\text {el300 }} \\
\text { reduces student's level of } \\
\text { attention during activities }^{\text {dl60 }} \text { ). }\end{array}$ \\
\hline 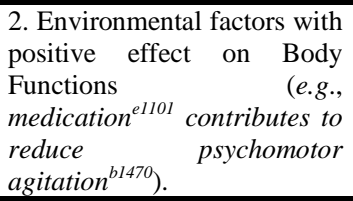 & 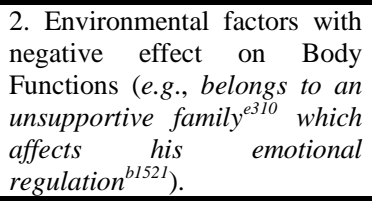 \\
\hline
\end{tabular}

A global increase of references specifying barriers and facilitators effect on functioning components was verified (figure 3 ), $F(4,136)=6.87$; $p<.001, \eta_{\mathrm{p}}{ }^{2}=.17$. Although both with statistical significance, the expansion of references to barriers influence was higher on the description of their impact on Activities and Participation, $t(139)=4.41$; $p<.001, d=.37$, than in Body Functions, $t(139)=2.15$; $p=.04, d=.18$. The increased number of mentions to facilitators effects was mainly achieved by the description of their impact on Activities and 
Participation, $t(139)=2.54 ; p=.01, d=.21$, without significant changes regarding the number of relations with Body Functions, $t(139)=1.47 ;$ n.s. .
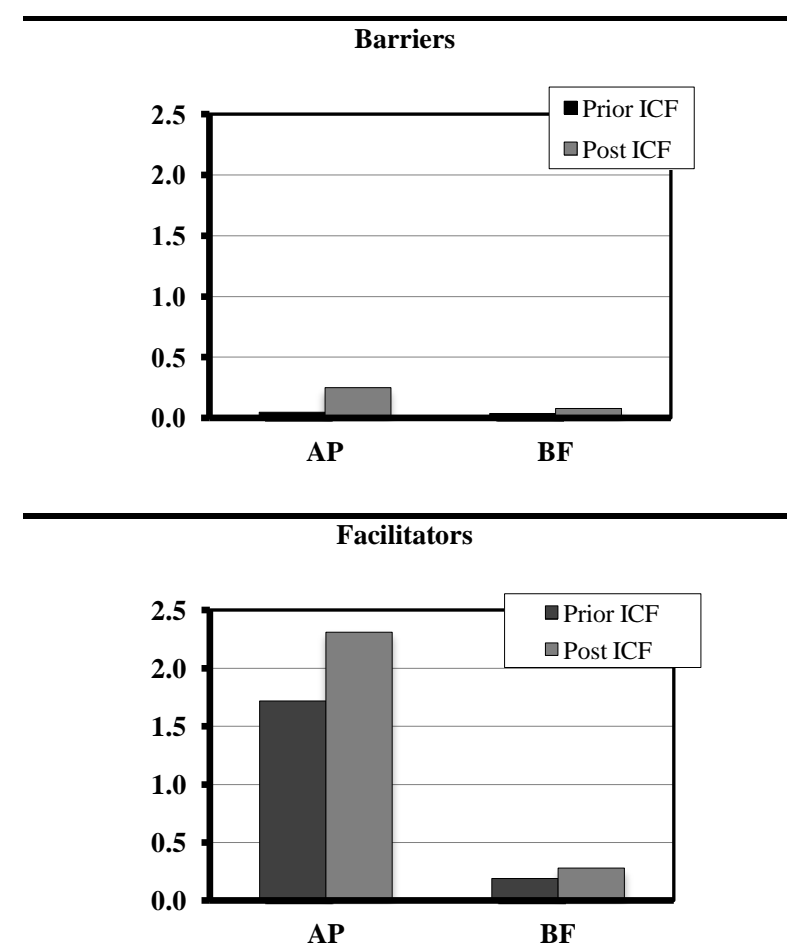

Figure 3. Mean references to environmental barriers and facilitators linked to functioning components Activities and Participation (AP) and Body Functions (BF) - on assessment processes

Among the references to the linkage between environmental factors and students' functioning, more than $90 \%$ reported the impact of facilitators. From those, $89 \%$ were related to student's performance on Activities and Participation.

On intervention plans the described relations between environmental factors and functioning components were only of positive nature: documenting the the introduction of some method (environmental strategy) to induce positive changes on student's Body Functions and Activities and Participation (Table 4).

Table 4. Documented types of relation between environmental factors and functioning components on intervention processes (examples) Facilitators

\begin{tabular}{l} 
Facilitators \\
\hline 1.Environmental factors with positive effect on Activities and \\
Participation $\left(e . g .\right.$, using concrete materials ${ }^{\text {el30 }}$ to support \\
counting activities $\left.{ }^{\text {dI50I }}\right)$. \\
\hline 2.Environmental factors with positive effect on Body \\
Functions $\left(e . g .\right.$, providing computer games $^{\text {el30 }}$ to stimulate \\
attention $^{\text {b140 }}$ and memory ${ }^{\text {bi44 }}$ functions $)$.
\end{tabular}

There was a global increase on environmental factors (supports) linked to the goals and objectives reported on functioning components, $F(2,138)=$ $3.75 ; p=.03, \eta_{\mathrm{p}}{ }^{2}=.05$. This improvement was mainly achieved by the higher number of references to environmental factors supporting student's performance on Activities and Participation ( $p=.01)$.

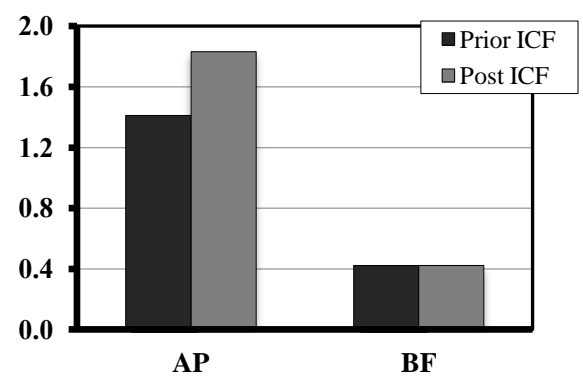

Figure 4. Mean references to environmental facilitators linked to functioning components Activities and Participation (AP) and Body Functions (BF) - on intervention processes

Despite the improvement achieved on a comprehensive view of environmental factors influence or interaction with human functioning, the mean number of environmental factors linked with functioning components is still a reduced part of the global references to the environment:

- On assessment processes, among a mean of 7 references to environmental factors only 3 were explicitly related with functioning components;

- On intervention processes among a mean of 10 references to environmental factors only 2 were explicitly related with functioning components.

On the examined IEPs, the environmental approach embraces mainly a list of factors implied on students' life without describing their effect on functioning.

\subsection{Congruence between environmental factors used on intervention and the assessment information}

Environmental habilitation means the reduction of barriers and the introduction of environmental facilitators detected on assessment process. Therefore its implementation demands congruence between assessed items and those used for intervention. In order to measure the congruence between assessed factors and those used on intervention processes, we identified the amount of environmental codes that were identical on assessment and on intervention processes.

IEP's designed after the ICF use revealed an increased proportion of environmental factors used 
as intervention strategies that were grounded on assessed environmental items, $t(139)=4.76 ; p<.001$; $d=.37$. Among all environmental strategies used on intervention, $48 \%$ were mentioned on assessment process on IEP's designed after ICF use, and $29 \%$ on those developed before the ICF use.

\subsection{Nature of environmental factors considered on assessment and intervention processes}

The ultimate test of the ICF impact on supporting the implementation of the environmental approach analyzed whether it promoted a wider use of environmental elements on assessment and intervention processes.

Students functioning profiles, were addressed with a mean of two environmental factors on the assessment process prior to the ICF use, and six post its implementation. The most frequent factors were mentioned in more than $25 \%$ and $34 \%$ of the examined assessment processes developed before and after the ICF use, respectively. The ICF use expanded environmental references from adapted educational methods (e1301) and teachers' support (e330) to descriptions that also included references to family support (e310) and attitudes (e410), peers support (e325) and special education services (e5853).

Concerning intervention processes, no significant differences were detected in environmental codes registered on both phases - prior and post ICF. The most frequent factors were identified in more than $68 \%$ and $54 \%$ of the examined intervention plans designed before and after the ICF use, respectively. In both phases, most cases mentioned general education methods (e1300), adapted education methods (e1301), and teachers' support (e330) as intervention strategies.

Regarding the scope of environmental elements described, we quantified the number of references on accessibility, accommodation, resources availability, social support or equality dimensions. As observed in figure 4 , the expanded mentions to environmental references on students' functioning was noticed in all dimensions, $F(5,135)=36.13 ; p<.001, \eta_{\mathrm{p}}{ }^{2}=.57$.

Bonferroni test located significant differences between both moments on accessibility $(p=.002)$, resources availability $(p<.001)$, accommodation $(p=.02)$ and social support $(p<.001)$ dimensions. In both moments there were few mentions to equality and accessibility (figure 5).

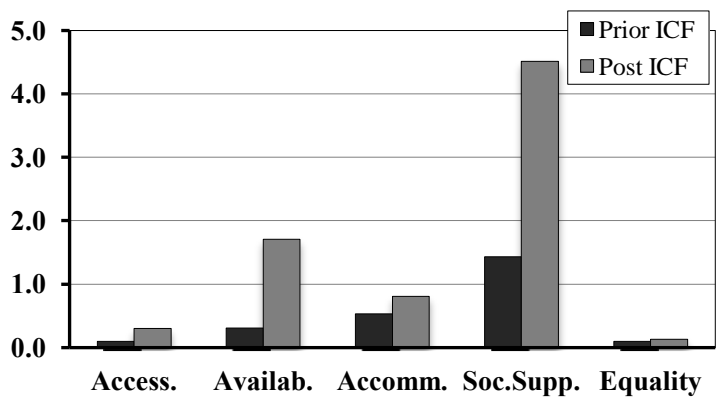

Figure 5. Mean references to each environmental dimension on assessment processes

Environmental references on student's functioning profiles designed before the ICF use were mainly centered on social support and accommodation, while post ICF functioning profiles were, besides social support, more focused on resources availability.

As verified on assessment processes, the larger emphasis on environmental context in intervention planning meant a higher number of references to the majority of environmental dimensions (figure 6), $F(5,135)=3.22 ; p=.009, \eta_{\mathrm{p}}{ }^{2}=.11$. This increase was achieved mainly by a higher attention on resources availability $(p=.02)$ and on accommodations $(p=.003)$. There were no mentions on accessibility and equality dimensions.

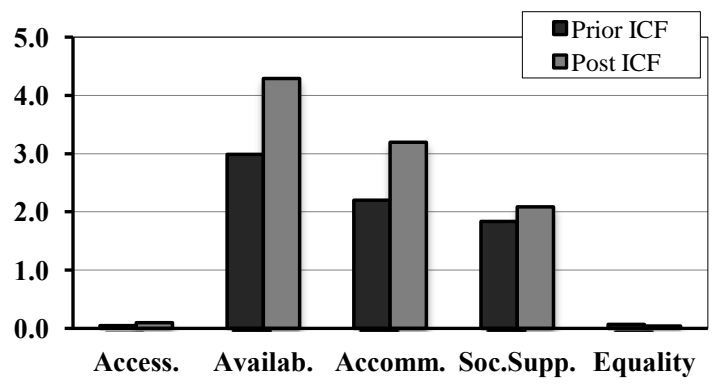

Figure 6. Mean references to each environmental dimension on intervention processes

Contrary to assessment process, the social support wasn't the principal focus of intervention processes. On the examined plans the resources availability and the accommodations were the dimensions more frequently mentioned in both phases.

\section{Discussion}

Portugal was the first country to formally introduce the ICF framework as the basis for guiding assessment and intervention processes within the special education field. The present study made use of textual analyses to examine whether the ICF compulsory use on the Portuguese special education 
system, is promoting a more extensive usage of the environmental approach.

Results revealed that the assessment and the intervention processes of a same student include more references to environmental factors and to their influence on students' functioning when using the ICF framework. On assessment processes, this increase was not only yielded on the number of mentions to environmental factors but also on the nature of environmental elements considered. Besides adapted methods of teaching and teacher's specialized support, current assessment processes also acknowledge natural setting resources as peers and parents support.

Although the mention to peers and parents support, intervention plans are still mainly restricted to adapted methods of education and teachers' support. In fact, not considering environmental facilitators - peers and parents support - as key elements of intervention strategies, suggests professionals' disbelief in their capacity to influence students' learning and development. Academic success remains more associated to resources availability rather than to social support or opportunities for equity.

There are two explanations for IEPs' interventions less expressive changes: (1) the reported lack of comprehensive tools that support problem solving approaches, using assessment information to define intervention goals and strategies [14]; (2) the reduced time to implement and integrate the new practices - two years since the decree-law endorsement. Indeed, the accommodation of new practices is achieved through different stages [26]. A substantial body of literature suggests that best environmental habilitation practices require a comprehensive view of how environmental factors impact on students' functioning [2, 3, 27].

In fact, the results indicated that the ICF use improved comprehensive descriptions, with increased mentions to positive forms of functioning supported by environmental facilitators. Despite the broader attention provided to person-environment interactions, references to barriers influence remained almost inexistent. Our findings show that the current practices mirror the concern of covering the variety of environmental elements that should be considered, but not yet a full understanding of their linkages to student's functioning.

\section{Conclusion}

This study indicates that the ICF was a step forward on inclusive practices through the formalization of the biopsychosocial model use. The ICF use improved the characterization of environmental factors. However, the environmental approach is still implemented as a formal accomplishment from a policy standpoint. The matching between Environmental Factors and students' functioning components (Body Functions and Activities and Participation) was seen as a guiding principle for ICF use improvement.

In future work, other factors' influence on assessment and intervention practices must be explored, such as teams' composition and training in using the ICF for educational purposes.

\section{References}

[1] L. Florian, J. Hollenweger, R. Simeonsson, K. Wedell, S. Riddell, L. Terzi, and A. Holland, "Cross-Cultural Perspectives on the Classification of Children with Disabilities", The Journal of Special Education 40(1), 2006, pp. 36-45.

[2] J. Thompson, M. Wehmeyer, and C. Hughes, "Mind the gap! Implications of a person-environment fit model of intellectual disability for students, educators, and schools", Exceptionality 18(4), 2010, pp. 168-181.

[3] R. Schalock, D. Coulter, V. Bradley, S. BorthwickDuffy, W. Buntinx et al., Intellectual Disability: definition, classification and systems of supports, American Association on Intellectual and Developmental Disabilities, Washington, 2010.

[4] J. Suls, and A. Rothman, "Evolution of the Biopsychosocial Model: Prospects and Challenges for Health Psychology", Health Psychology 23(2), 2004, pp. 119-125.

[5] WHO, International Classification of Functioning, Disability and Health - Version for Children and Youth: ICF - CY, World Health Organization, Geneva, 2007.

[6] R. Guscia, S. Ekberg, J. Harries, and N. Kirby, "Measurement of Environmental Constructs in Disability Assessment Instruments", Journal of Policy and Practice in Intellectual Disabilities 3(3), 2006, pp.173-180.

[7] A. Sameroff, "A Unified Theory of Development: A Dialectic Integration of Nature and Nurture", Child Development, 81(1), 2010, pp. 6-22.

[8] L. Eriksson, "The relationship between school environment and participation for students with disabilities", Pediatric Rehabilitation 8(2), 2005, pp. 130139.

[9] D. Fisher, N. Frey, and J. Thousand, "What do special educators need to know and be prepared to do for inclusive schooling to work?" Teacher Education and Special Education 26(1), 2003, pp. 42-50. 
[10] J. Bickenbach, "Disability, human rights, law and policy in creation", Handbook of disability studies, Thousand Oaks, Ca: Sage, 2001, pp. 565-574.

[11] W. Finlay, and E. Lyons, "Rejecting the Label: A social constructionist analysis", Mental Retardation 43(2), 2005, pp. 120-134.

[12] D. Kaplan, and S. Coogan, "The next advancement in counseling: The bio-psycho-social model", Vistas: Compelling perspectives on counseling, 2005, pp. 17-25.

[13] M. Sanches-Ferreira, Educação Regular, Educação Especial - uma história de separação, Edições Afrontamento, Porto, 2007.

[14] M. Sanches-Ferreira, R. Simeonsson, M. Maia, S. Pinheiro, A. Tavares, and S. Alves, Projecto da Avaliação Externa da Implementação do Decreto-Lei $n .^{\circ} 3 / 2008$, DGIDC, Lisboa, 2010.

[15] M. Maia, and P. Lopes-dos-Santos, "Práticas em Educação Especial à Luz do Modelo Biopsicossocial: $\mathrm{O}$ Uso da CIF-CJ como Referencial na Elaboração dos Programas Educativos Individuais", Actas do VII Simpósio Nacional de Investigação em Psicologia, Minho, 2010.

[16] G. Whiteneck, "Validated Measures of Participation and the Environment from Craig Hospital: CHART and CHIEF", United Nations International Seminar on Measurement of Disability, New York, 2001.

[17] E. Horn, J. Lieber, S. Sandall, I. Schwartz, and S. Li, "Supporting young children's IEP goals in inclusive settings through embedded learning opportunities", Topics in Early Childhood Special Education 20, 2002, pp. 208223.

[18] S. Sandall, I. Schwartz, G. Joseph, H. Chou, E. Horn, J. Lieber, et al., Building blocks for teaching preschoolers with special needs, Brookes, Baltimore, 2008.

[19] J. Lieber, I. Schwartz, S. Sandall, E. Horn, and R. Wolery, "Curricular considerations for young children in inclusive settings", Early childhood curriculum: A review of the research, Teachers College Press, New York, 1999, pp. 243-264.

[20] G. Whiteneck, P. Fougeyrolles, K. Gerhart, "Elaborating the Model of Disablement.", Assessing Medical Rehabilitation Practices: The Promise of Outcomes Research, Paul H. Brooks Publishing Co., 1997, pp.91-102.

[21] L. Capucha, F. Pereira, A. Crespo, C. Correia, F. Cavaca, F. Croca, et al., Educação Especial - Manual de
Apoio à Prática, DGIDC, Lisboa, 2008.

[22] D. McAnaney, "The ICF as a Framework for disability policy design and deployment", European Platform for Rehabilitation, 2007.

[23] U. Graneheim, and B. Lundman, "Qualitative content analysis in nursing research: concepts, procedures and measures to achieve trustworthiness", Nurse Educ Today 24(2), 2004, pp. 105-12.

[24] A. Cieza, S. Geyh, S. Chatterji, N. Kostanjsek, B. Üstün, and G. Stucki, "ICF linking rules: an update based on lessons learned", J Rehabil Med 37(2), 2005, pp. 212218.

[25] T. Dijk, "Semantic Discourse Analysis", Handbook of Discourse Analysis, Academic Press, London, 1985, pp.103-112.

[26] C. Estabrooks, D. Thompson, J. Lovely, A. Hofmeyer, "A Guide to Knowledge Translation Theory", The Journal of Continuing Education in the Health Professions 26(1), 2006, pp.25-36.

[27] R. Simeonsson, M. Leonardi, E. Bjorck-Akensson, J. Hollenweger, D. Lollar, et al., "ICF-CY: a universal tool for practice policy and research", Metting of WHO collaborating centres for the family of international classifications, Tunisia, 2006. 